culture of independent schools. Most importantly, I hope it encourages researchers to engage more with independent schools in looking for alternative perspectives on managerialism and anti-managerialism.

Mike Carslaw, Ardingly College, West Sussex, UK

(C) 2007, Mike Carslaw

\title{
Adult literacy as social practice: more than skills
}

Uta Papen, 2005

London, Routledge

$£ 70$ (hbk), I 76 pp.

ISBN 0-4I53-5376-2

Considerable attention is being paid to the professional development of practitioners involved in adult literacy, language and numeracy (ALLN). This book is a very welcome addition to an increasing literature on ALLN, how it is defined, how it is used and what the implications are for practitioners and learners. In particular, this volume has a key aim to introduce readers to the social practice view of literacy and its implications for teaching and learning ALLN.

The initial chapters cover the theory of literacy as social practice and then move on to discuss the implications for policy and practice. A primary aim is to show how theory and research can inform policy and practice and how this can be achieved through collaboration between research and practice.

A central tenet of the social practice view of literacy is that by understanding the role of literacy in learners' lives, it is possible to apply this understanding in relation to the literacy demands in work, home and in social and familial relationships. This approach can also address how ALLN is taught and learnt and it can help contribute to policy in the UK and further afield.

Each chapter contains short readings to further illuminate and expand issues raised, followed by research activities, suggested issues for reflection and additional reading. For example, in chapter one, which sets out theoretical perspectives on reading and writing, readers are encouraged to critically examine their own assumptions about literacy and numeracy and there are two readings, one by Mary Hamilton discussing four 'strands' or ideologies of literacy: emancipatory, social control, cultural missionary work and remedial. A second article by Jean Searle discusses how literacy is not a neutral concept. Readers are then asked to collect definitions about literacy and apply the ideologies outlined by Hamilton and to reflect on whether their own programmes fit these too.

In part I of the book, Uta examines the 'new' way of looking at reading and writing. She identifies the literacy debates about functional skills versus social practice, using the example of making a journey by train to illustrate how literacy and numeracy are important 
components of the social practice of traveling by train. People need to be able to read and use timetables and to purchase tickets (in England, with so many options, this is no mean feat!). Importantly, the integration of literacy and numeracy is recognized in this activity.

Part 2 discusses how policy and practice have evolved in Britain and examines the current Skills for Life Strategy in England by drawing upon a critical analysis of policy discourse. The final chapter considers the implications for using a social practice view of literacy in the curriculum, returning the reader once more to the pragmatic and everyday need to make sense of how ALLN is taught and learnt.

To a new practitioner, all these concepts will be challenging, although I was a little surprised that the social practices view of literacy is claimed to be new, given that new literacy studies were first developed twenty years ago. It is unfortunate that attention has been primarily focused on literacy throughout the book, given the interesting questions around how language and numeracy can be examined as social practices. Despite these reservations, I found the book immensely clear and coherent. The key issues and tensions in the field of ALLN were captured concisely. There are, of course, issues still to be resolved. Do we know that a social practices view of ALLN is more effective in the classroom? As Uta points out in the final chapter, we do not actually have a theory of learning that fits the social practices view of literacy and we need to develop models and strategies and test these out as we continue to research and develop the practice of ALLN.

This book provides a good starting point for taking on that challenge and deserves to be read by practitioners, researchers and policy makers.

Yvonne Hillier, University of Brighton, UK

(C) 2007, Yvonne Hillier

Academic freedom at the dawn of a new century: how terrorism, Governments and culture wars impact free speech

Evan Gerstmann and Matthew J. Streb (Eds), 2006

Palo Alto, Stanford University Press

$\$ 50$ dollars (cloth), 260 pp.

ISBN 0-8047-5444-6

Non-American historians of the culture and society of the US know that the country can from time to time exhibit its best and its worst self. The 14th amendment to the Constitution, which was designed to ensure equality for former slaves and their descendants, degenerated into a licence for abuse by private corporations ('persons' in law) at the turn of the twentieth century. Conversely, almost all sophisticated observers knew that as a result of the peculiar institution of the detention centre at Guantanamo Bay, the current President would end up in the Supreme Court, and that he would lose. 